Original Study

\title{
Circulating Micronutrient Biomarkers Are Associated With 3 Measures of Frailty: Evidence From the Irish Longitudinal Study on Ageing
}

\author{
Aisling M. O’Halloran $\mathrm{PhD}^{\mathrm{a}, *}$, Eamon J. Laird $\mathrm{PhD}^{\mathrm{a}}$, Joanne Feeney $\mathrm{PhD}^{\mathrm{a}}$, \\ Martin Healy PhD ${ }^{b}$, Rachel Moran $\mathrm{PhD}^{\mathrm{c}}$, Stephen Beatty MD ${ }^{\mathrm{c}}$, John M. Nolan $\mathrm{PhD}^{\mathrm{c}}$, \\ Anne M. Molloy PhD ${ }^{\mathrm{d}}$, Rose Anne Kenny MD ${ }^{\mathrm{a}, \mathrm{e}}$ \\ ${ }^{a}$ The Irish Longitudinal Study on Ageing, Medical Gerontology, Trinity College, Dublin, Ireland \\ ${ }^{\mathrm{b}}$ Department of Biochemistry, Laboratory Medicine and Molecular Pathology, St James's Hospital, Dublin, Ireland \\ ${ }^{\mathrm{c}}$ Macular Pigment Research Group, Nutrition Research Centre Ireland, School of Health Science, Waterford Institute of Technology, Waterford, Ireland \\ ${ }^{\mathrm{d}}$ Clinical Medicine, Trinity College, Dublin, Ireland \\ ${ }^{\text {e } M e r c e r ' s ~ I n s t i t u t e ~ f o r ~ S u c c e s s f u l ~ A g e i n g, ~ S t . ~ J a m e s ' s ~ H o s p i t a l, ~ D u b l i n, ~ I r e l a n d ~}$
}

\section{Keywords:}

Micronutrients

biomarkers

frailty

aging

\begin{abstract}
A B S T R A C T
Objectives: To examine the associations between 3 frailty instruments and circulating micronutrients in a large representative sample of older adults.

Design: Cross-sectional data from a nationally representative cohort study conducted between October 2009 and July 2011.

Participants and setting: Adults age $\geq 50$ years $(n=4068)$ living in the community in Ireland.

Measurements: Circulating micronutrients (lutein, zeaxanthin, folate, vitamin B-12, and vitamin D) were measured, transformed, and standardized. Frailty was assessed using the Frailty Phenotype, the Frailty Index, and the FRAIL Scale (fatigue, resistance, ambulation, illnesses, and loss of weight), instruments. Multinomial logistic regression determined associations between micronutrients and prefrailty or frailty. Models were adjusted for sociodemographic, lifestyle, health, and seasonal factors.

Results: Adjusting for age, sex, and educational attainment, all 3 measures of frailty were associated with lower levels of lutein [relative risk ratios (RRRs): 0.43-0.63], zeaxanthin (RRRs: 0.49-0.63), and vitamin D (RRRs: 0.51-0.75), and with the accumulation of micronutrient insufficiencies (RRRs: 1.42-1.90). Attenuated but significant associations were also observed with all measures of prefrailty for lutein, vitamin $\mathrm{D}$, and number of micronutrient insufficiencies. The associations with frailty persisted following additional adjustment for social, lifestyle, and health and seasonal factors, and following multiple test correction.

Conclusions and implications: We have presented the most consistent evidence in the largest study to date that micronutrient concentrations are associated with prefrailty and frailty in older adults. Our data suggest that low micronutrient status has potential as an easily modifiable marker and intervention target for frailty and supports further investigation into micronutrient supplementation and fortification to prevent frailty and disability among older adults.
\end{abstract}

(c) 2019 AMDA - The Society for Post-Acute and Long-Term Care Medicine.
This work was supported by the Irish Government Department of Health; Irish Government Department of Agriculture, Fisheries and the Marine; the Atlantic Philanthropies; and Irish Life PLC. AOH and JF were supported by Institute of Public Health - Division of Ageing Research and Development (formerly Centre for Ageing Research and Development - CARDI) Leadership in Ageing Research Awards.

The authors declare no conflicts of interest.
* Address correspondence to Aisling M. O’Halloran, PhD, The Irish Longitudinal Study on Ageing, Medical Gerontology, Trinity College, Lincoln Gate, Trinity College, Dublin 2, Ireland.

E-mail address: aiohallo@tcd.ie (A.M. O'Halloran). 
Not everyone of the same age is at the same risk of adverse health outcomes. Frailty captures this differential risk that is distinct from, but related to, chronological aging. ${ }^{1,2}$ Frailty is characterized by multisystem loss of physiological reserve, systemic decompensation in response to stressors, and increased risk of adverse outcomes including falls, disability, and mortality. Frailty is modifiable, representing a transition between healthy aging and disability, ${ }^{1}$ and is a target condition for increasing healthy life years. Comprehensive geriatric assessment (CGA) is the gold standard for diagnosing and treating frailty, ${ }^{3}$ but is unfeasible for systematic case finding at the population level. The frailty phenotype, the Frailty Index (FI), and the FRAIL (fatigue, resistance, ambulation, illnesses, and loss of weight) Scale are widely accepted screening instruments for frailty at the population level. ${ }^{4-6}$ Internationally the prevalence of frailty is $4 \%-59 \%$ among adults age $\geq 65$ years, depending on the frailty instrument and population studied. $^{7}$

Frailty impacts multiple functional domains including nutrition, strength, mobility, physical activity, cognition, and social engagement. ${ }^{8}$ Inadequate dietary intake has been implicated in the increased risk of chronic diseases and frailty. ${ }^{7,9-15}$ The importance of adequate nutrition to postponing frailty and sarcopenia (a central component of frailty) among older adults is well-established. ${ }^{16}$ This relationship is bidirectional, however. Older adults with frailty often experience accelerated aging including more pronounced appetite suppression and/or malabsorption of macro- and micronutrients. This can lead to chronic deficiencies resulting in further and often unrecoverable physiological and functional decline. ${ }^{17,18}$

Xanthophyll carotenoids have long been implicated in improving visual outcomes and disease progression in individuals with agerelated macular degeneration. More recently, a putative protective role for these compounds in other chronic diseases of aging has emerged, including cancer, ${ }^{19}$ cardiovascular disease ${ }^{20}$ and diabetes, ${ }^{21}$ neurodegenerative disease, ${ }^{22}$ and bone health. ${ }^{23}$ The biological mechanisms underpinning these associations are centered on the function of carotenoids at the cellular level. They can act as antioxidants, primarily by free radical scavenging and stabilizing reactive radicals. ${ }^{24}$ There is also increasing evidence that they are antiinflammatory, via their interactions with various intracellular signaling cascades. ${ }^{25,26}$ Finally, carotenoids promote cell membrane stabilization. $^{27}$ These protective cellular mechanisms likely explain why inverse associations between carotenoid levels and disease risk have been observed for several age-associated conditions with an inflammatory or oxidative stress etiology. Consequently, they may influence multisystem dysregulation, which has been proposed to underlie the frailty syndrome.

The B-vitamin micronutrients vitamin B-12 and folate have also been associated with the chronic conditions of aging such as cognitive dysfunction, diabetes, and cardiovascular disease. ${ }^{28,29}$ However, the mode of action is considered to be through the methylation cycle pathway and the stabilization of co-enzyme metabolic pathways. ${ }^{30,31}$ Combined, these micronutrients have a modulating effect on the entire body system from regulation of DNA synthesis/repair and methylation, to acting as coenzymes in a substantial proportion of the processes that underpin every aspect of cellular functioning including systemic inflammation. ${ }^{28}$ Thus, these B-vitamins are proposed to be a key corner stone in the understanding of frailty initiation and progression.

Vitamin D is a key determinant of bone health and the muscoskeletal system. ${ }^{32}$ However, recent evidence has also suggested a role in chronic disease with deficiency associated with diabetes, cardiovascular disease, cancer, inflammaging, and mortality. ${ }^{33,34}$ It is thought vitamin $\mathrm{D}$ acts through the vitamin $\mathrm{D}$ receptor (which is found on the majority of cells) at the transcription level and through its immunomodulating effects on the immune and wider organ-tissue system. $^{35,36}$

Many studies have focused on the impact of macronutrient (eg, protein) intake on frailty, but fewer have reported associations between frailty and these circulating micronutrients. ${ }^{13,15,37-40}$ The previous studies exhibited some limitations including modest sample sizes, female-only samples, and samples that did not include younger older adults age $50-59$ years. In addition, all studies measured a single frailty outcome (predominantly the frailty phenotype) and most did not test for associations with prefrailty. ${ }^{13,15,37-40}$ Although evidence linking low vitamin D levels alone and incident phenotype frailty has been consistent from meta- and longitudinal analyses, ${ }^{41-46}$ only 1 study found an association between total carotenoids and incident phenotype frailty. ${ }^{15}$

The evidence described of individual micronutrient associations with conditions in physiological systems known to be implicated in frailty, coupled with the few studies that examined frailty associations directly, suggest that sufficient micronutrient levels may protect against frailty (Figure 1). Examining this panel of 5 micronutrient biomarkers could provide additional evidence to improve risk prediction for frailty and suggest easily modifiable intervention targets. Without a universal instrument and the heterogenous pathogenesis of frailty, associations between micronutrient biomarkers and prefrailty/

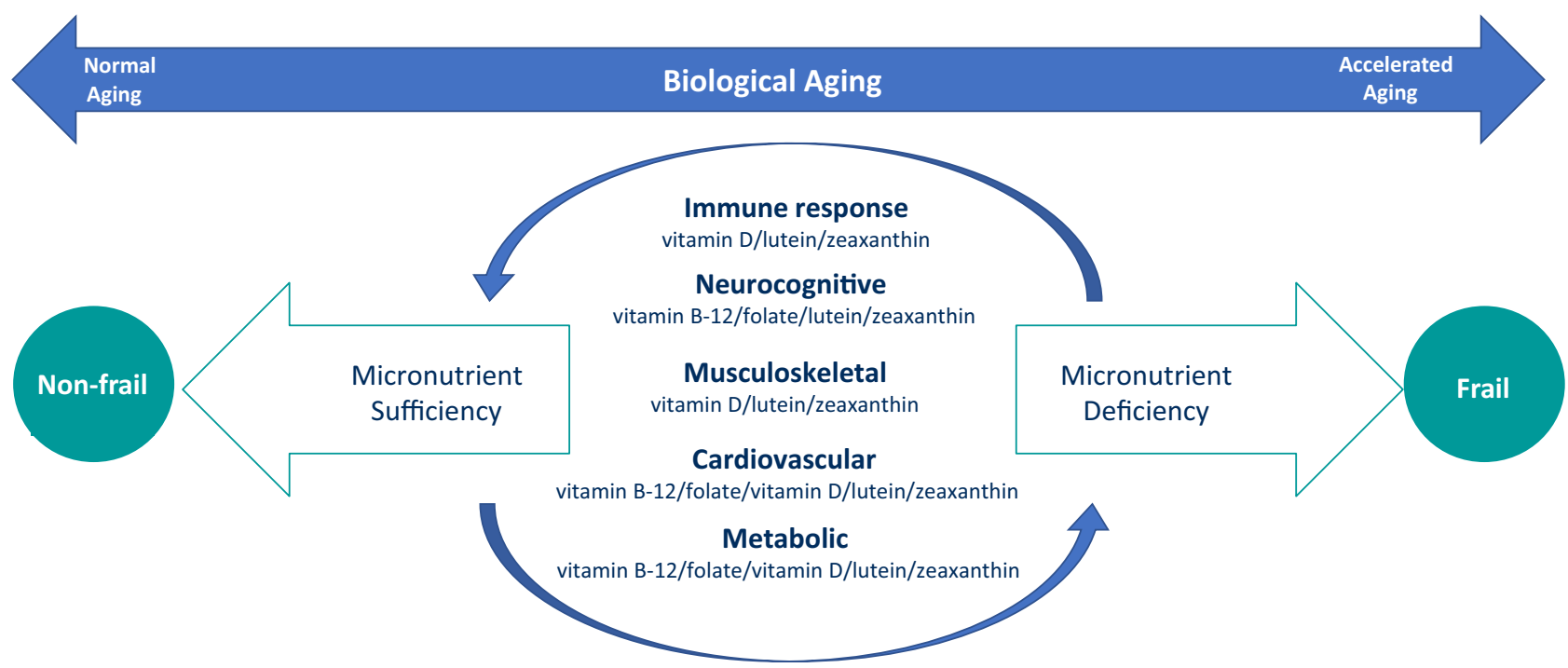

Fig. 1. Proposed model of how micronutrient status impacts the physiological systems that underpin frailty, a measure of accelerated biological aging. 
frailty are inconsistent. Using different frailty instruments in tandem could provide stronger, more reliable evidence for such associations. The aim of this study was to assess whether the circulating micronutrient biomarkers (lutein, zeaxanthin, vitamin B-12, folate, and vitamin D) were consistently and progressively associated with 3 measures of frailty in a single large representative sample of adults age $\geq 50$ years.

\section{Methods}

Study Sample

Participants were members of The Irish Longitudinal Study on Ageing (TILDA), a nationally representative cohort of communitydwelling adults age $\geq 50$ years in the Republic of Ireland. Study sampling and data collection procedures have been described previously. ${ }^{47,48}$

In summary, the first wave of data collection was conducted between October 2009 and July 2011. At baseline, 8175 adults age $\geq 50$ years completed a computer-aided personal interview, representing a response rate of $62 \%$. Approximately $72.1 \%(n=5895)$ consented to, and participated in, a health assessment. Of those, 91.3\% $(\mathrm{n}=5656)$ provided blood samples for biobank archiving.

Study participants provided written informed consent in accordance with the Declaration of Helsinki guidelines, and ethical approval was granted by the appropriate Institutional Research Ethics Committee.

\section{Frailty Measurements}

Three widely utilized measures of frailty, namely Phenotype frailty, the deficit accumulation Frailty Index (FI), and the FRAIL (fatigue, resistance, ambulation, illnesses, and loss of weight) Scale were applied to participant data from wave 1 of TILDA as previously published. ${ }^{49}$ A detailed description is provided in Supplementary Material 1 and Supplementary Table 1.

\section{Demographic, Lifestyle, and Health Factors}

Participant information recorded included age, sex, highest level of educational attainment (primary/secondary/third level), and habitation status (living alone/with others). Individuals were asked about their smoking habits and categorized as never, past, or current smokers. Body mass index was derived from height and weight measures carried out during the health assessment and categorized as normal weight $\left(18.5-24.9 \mathrm{~kg} / \mathrm{m}^{2}\right)$, overweight $\left(25-29.9 \mathrm{~kg} / \mathrm{m}^{2}\right)$, and obese $\left(\geq 30.0 \mathrm{~kg} / \mathrm{m}^{2}\right)$. Data on cardiovascular conditions were ascertained by self-reported doctor's diagnosis (heart attack, heart failure, angina, hypertension, high cholesterol, stroke, transient ischemic attack, diabetes, abnormal heart rhythm, and other heart condition). Chronic conditions were ascertained by self-reported doctor's diagnosis (lung disease, asthma, arthritis, osteoporosis, cancer, Parkinson's disease, Alzheimer's disease, dementia, memory impairment, alcohol abuse, substance abuse, peptic ulcer, varicose ulcers, and cirrhosis/ liver disease). Each group of cardiovascular or chronic conditions were summed and coded into a 3-level variable for analysis denoting participants with 0,1 , and $\geq 2$ conditions. Global cognitive function was screened using the Mini-Mental State Examination score. The number of cognitive errors was determined by subtracting the number of incorrect responses from the maximum Mini-Mental State Examination score of 30 . The presence of depressive symptoms was ascertained as a score of $\geq 16$ from the 20 -item Center for Epidemiologic Studies Depression scale. Any dietary supplements taken on a daily basis (yes/no) were recorded and included both prescription and nonprescription supplements.

\section{Biochemical Analyses}

Nonfasting whole blood samples were collected between 09:30 and $16: 30$ by venipuncture into $10 \mathrm{~mL} \mathrm{~K} \mathrm{~K}_{2}$ EDTA (potassium ethylenediaminetetra-acetic acid) tubes (BD, Becton, Dickinson Limited, Oxford, UK) during the health assessments and were transported at $2^{\circ} \mathrm{C}-8^{\circ} \mathrm{C}$. Plasma and Buffy coats were separated from the blood samples within 48 hours of collection and archived at $-80^{\circ} \mathrm{C}$ until assayed. Unless stated otherwise, biomarker analyses were automated and carried out on archived plasma samples between 2014 and 2016 by an International Organization for Standardization accredited clinical pathology laboratory at a teaching hospital in Dublin, Ireland. A description of the biomarker analysis for lutein, zeaxanthin, vitamin D, vitamin B-12 and folate are provided in Supplementary Material $2 .^{50-54}$ The date of blood collection was documented and seasonality was determined: Winter (December-February), spring (March-May), summer (June-August), and autumn (September-November).

\section{Statistical Analysis}

The total sample size of adults age $\geq 50$ years at wave 1 was 8175 , and $52 \%$ were female. Individuals were excluded if they did not attend a health assessment $(\mathrm{n}=2280)$, did not consent to or provide a sufficient blood sample ( $\mathrm{n}=239)$, were missing any micronutrient measure $(\mathrm{n}=1171)$, had micronutrient levels more than 3 standard deviations from the mean ( $n=217)$, were missing data for any frailty measure $(n=111)$, and were missing data on covariates $(n=89)$. Thus, 4104 participants were excluded, leaving an analysis sample of 4068 (Figure 2). Statistical differences between the exclusion and analysis sample were investigated using logistic or multinomial logistic regression for categorical variables, bivariate linear regression analysis for normally distributed continuous variables, and negative binomial regressions for non-normally distributed right-skewed covariates (eg, number of cognitive errors).

Differences in the demographic, lifestyle, and health factors by frailty status for the 3 frailty instruments were investigated using multinomial logistic regression. Differences in micronutrient concentration levels by frailty status across the 3 frailty instruments were determined by unadjusted linear regression.

The US Institute of Medicine categorical cut-offs for insufficiency were applied for vitamin $\mathrm{D}(\leq 50.00 \mathrm{nmol} / \mathrm{L})$, vitamin $\mathrm{B}-12(<185.00$ $\mathrm{pmol} / \mathrm{L})$, and folate $(\leq 10.00 \mathrm{nmol} / \mathrm{L})$ to generate binary variables ( $1=$ insufficient $/ 0$ = sufficient) for each micronutrient. The lowest tertile of lutein and zeaxanthin were designated as insufficient in the absence of internationally accepted cut-offs. The 5 binary variables were summed to generate a count of insufficiencies for each participant ranging from 0 to 5 , and differences by frailty status and instrument were compared.

Micronutrient measures were log transformed and standardized to allow comparability of effect sizes such that 1-unit increase or decrease represented 1 standard deviation (SD) from the mean micronutrient concentration. Multinomial logistic regression determined associations between the transformed and standardized micronutrients (and number of micronutrient insufficiencies) and frailty status using 3 models. Model 1 was unadjusted, model 2 was minimally adjusted for age, age ${ }^{2}$, sex, and educational attainment, and model 3 was adjusted for age, age ${ }^{2}$, sex, educational attainment, living arrangements, smoking history, body mass index category, cardiovascular conditions, chronic conditions, depressive symptoms, global cognitive function (cognitive errors), intake of dietary supplements, and season when blood was drawn. All analyses were weighted to the general population age $\geq 50$ years.

An adjustment for multiple comparisons was made for each model (models 1 through 3 ) by controlling the false discovery rate (FDR) 


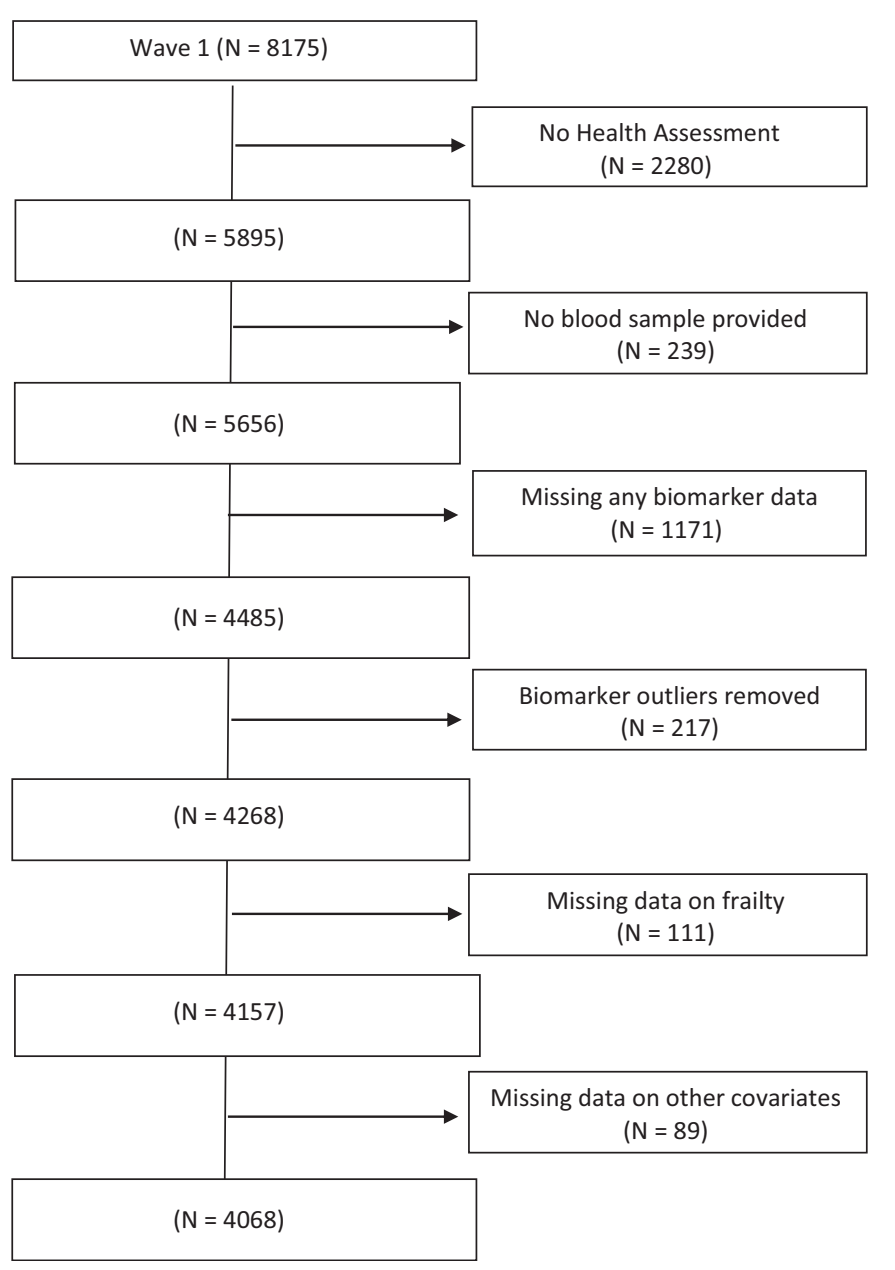

Fig. 2. Participant flow chart. using the Benjamini and Hochberg (1995) method, ${ }^{55}$ facilitated by the Smileplot package in Stata. Data were analyzed using Stata v 14 (StataCorp, College Station, TX).

\section{Results}

Analytical vs Excluded Sample

The analysis and excluded samples were compared across demographic, lifestyle, and health characteristics previously associated with frailty and micronutrient intake (Supplementary Table 2). The analysis sample was younger, had a lower percentage of female persons and higher educational attainment, and was less likely to live alone, be current smokers, be overweight or obese, and had higher levels of physical activity. They reported lower levels of frailty and prefrailty, cardiovascular and chronic conditions, disability, cognitive errors, and medication use, but higher levels of depressive symptoms. No difference in dietary supplements taken was observed.

\section{Sample Characteristics by Frailty Instrument and Status}

Differences in demographic, lifestyle, and health characteristics by frailty status and instrument are provided in Table 1. Compared with the nonfrail, the prefrail and frail participants were progressively older, with lower levels of educational attainment, and were more likely to live alone. This was consistent across the 3 frailty instruments. Female sex was associated with prefrailty for the FI and FRAIL instruments, and with FI frailty only. For all frailty measures, prefrailty and frailty were associated with smoking, obesity, low physical activity, disability, more cardiovascular and chronic conditions, poorer cognitive function, more depressive symptoms, higher medication use, and supplement use. The prefrail exhibited intermediate levels of each characteristic compared with the nonfrail and frail (Table 1).

Table 1

Participant Characteristics by Frailty Status for Phenotype, FI, and FRAIL Scale Instruments

\begin{tabular}{|c|c|c|c|c|c|c|c|c|c|}
\hline \multirow{2}{*}{$\frac{\text { Frailty Instrument }}{\text { Variable at Wave } 1 \text { (Range) }}$} & \multicolumn{3}{|l|}{ Phenotype } & \multicolumn{3}{|l|}{ FI } & \multicolumn{3}{|l|}{ FRAIL Scale } \\
\hline & Nonfrail & Prefrail & Frail & Nonfrail & Prefrail & Frail & Nonfrail & Prefrail & Frail \\
\hline$\%(n)$ & 68.8 (2799) & $29.3(1192)$ & $1.9(77)$ & 60.9 (2479) & $29.8(1211)$ & $9.3(378)$ & $80.7(3282)$ & $18.0(733)$ & $1.3(53)$ \\
\hline Age: y, mean (SD) & $60.7(7.6)$ & $63.6(9.0)^{\mathrm{c}}$ & $69.7(11.9)^{\mathrm{c}}$ & $59.6(7.3)$ & $64.1(8.4)^{\mathrm{c}}$ & $67.6(9.2)^{\mathrm{c}}$ & $61.2(8.0)$ & $63.5(9.1)^{c}$ & $65.9(8.5)^{\mathrm{b}}$ \\
\hline$\geq 50 \mathrm{y}, \%(\mathrm{n})$ & 68.8 (2799) & $29.3(1192)$ & $1.9(77)$ & 60.9 (2479) & $29.8(1211)$ & $9.3(378)$ & $80.7(3282)$ & $18.0(733)$ & $1.3(53)$ \\
\hline$\geq 65 \mathrm{y}, \%(\mathrm{n})$ & $60.9(860)$ & $35.6(503)$ & $3.5(50)$ & $43.9(620)$ & $39.6(559)$ & $16.6(234)$ & $77.1(1090)$ & $20.9(295)$ & $2.0(28)$ \\
\hline$\geq 75 \mathrm{y}, \%(\mathrm{n})$ & $40.5(138)$ & $50.4(172)$ & $9.1(31)$ & $24.7(91)$ & $45.5(115)$ & $27.9(95)$ & $6.9(228)$ & $30.8(105)$ & $2.3(8)$ \\
\hline Sex: female, \% (n) & $51.3(1435)$ & $54.1(645)$ & $53.3(41)$ & $49.1(1216)$ & $56.2(681)^{\mathrm{c}}$ & $59.3(224)^{c}$ & $50.1(1643)$ & $61.5(451)^{c}$ & $50.9(27)$ \\
\hline Education: primary level, \% (n) & $19.6(548)$ & $26.9(320)^{c}$ & $37.7(29)^{b}$ & $17.1(423)$ & $26.8(324)^{c}$ & $39.7(150)^{c}$ & $20.0(655)$ & $29.1(213)^{c}$ & $54.7(29)^{c}$ \\
\hline Living arrangements: alone, \% (n) & $14.5(407)$ & $19.5(232)^{b}$ & $28.6(22)^{b}$ & $13.2(326)$ & $19.7(239)^{b}$ & $25.4(96)^{c}$ & $14.9(488)$ & $21.0(154)^{c}$ & $35.9(19)^{c}$ \\
\hline Smoking: current, \% (n) & $13.0(364)$ & $18.0(215)^{b}$ & $28.6(22)^{b}$ & $14.0(346)$ & $15.3(185)^{a}$ & $18.5(70)^{c}$ & $13.2(432)$ & $20.7(152)^{c}$ & $32.1(17)^{c}$ \\
\hline Physical activity: low, \% (n) & $15.8(443)$ & $49.3(588)^{c}$ & $87.0(67)^{c}$ & $22.2(549)$ & $30.6(370)^{c}$ & $47.4(179)^{\mathrm{c}}$ & $23.8(782)$ & $38.6(283)^{c}$ & $62.3(33)^{c}$ \\
\hline Body mass index: overweight, \% (n) & $45.3(1267)$ & $42.5(507)$ & $35.1(27)$ & $47.0(1164)$ & $41.5(503)$ & $35.5(134)$ & $45.3(1,488)$ & $40.4(296)$ & $32.1(17)$ \\
\hline Obese, \% (n) & $32.1(899)$ & $36.7(438)^{c}$ & $39.0(30)$ & $28.9(717)$ & $38.4(465)^{c}$ & $48.9(185)^{\mathrm{C}}$ & $32.4(1062)$ & $38.6(283)^{c}$ & $41.5(22)$ \\
\hline \multicolumn{10}{|l|}{ No. of chronic conditions } \\
\hline $1, \%(n)$ & $32.6(912)$ & $36.8(439)^{\mathrm{c}}$ & $42.9(33)^{\mathrm{c}}$ & $28.7(708)$ & $45.5(551)^{\mathrm{c}}$ & $33.1(125)^{\mathrm{c}}$ & $33.3(1093)$ & $37.8(277)^{\mathrm{c}}$ & $26.4(14)^{\mathrm{b}}$ \\
\hline$\geq 2, \%(\mathrm{n})$ & $13.8(386)$ & $23.9(285)^{c}$ & $37.7(29)^{c}$ & $6.5(160)$ & $27.4(332)^{\mathrm{c}}$ & $55.0(208)^{c}$ & $12.7(417)$ & $34.1(250)^{c}$ & $62.3(33)^{c}$ \\
\hline \multicolumn{10}{|l|}{ No. of CV conditions } \\
\hline $1, \%(n)$ & $34.6(969)$ & $30.4(363)$ & $22.1(17)$ & $36.1(896)$ & $32.0(387)^{\mathrm{c}}$ & $17.5(66)^{\mathrm{c}}$ & $34.6(1136)$ & $28.1(206)$ & $13.2(7)$ \\
\hline$\geq 2, \%(\mathrm{n})$ & 24.9 (697) & $36.6(436)^{c}$ & $53.3(41)^{c}$ & $11.3(281)$ & $50.0(605)^{c}$ & $76.2(288)^{c}$ & $24.7(811)$ & $44.1(323)^{c}$ & $75.5(40)^{\mathrm{c}}$ \\
\hline $\begin{array}{l}\text { Global cognition: MMSE errors, } \\
\text { mean (SD) }\end{array}$ & $1.2(1.7)$ & $1.7(1.9)^{\mathrm{a}}$ & $2.9(2.8)^{b}$ & $1.2(1.5)$ & $1.5(1.7)$ & $2.1(2.6)^{b}$ & $1.3(1.8)$ & $1.6(1.9)$ & $3.3(2.8)^{\mathrm{b}}$ \\
\hline Depression: CES-D score $\geq 16, \%$ (n) & $3.6(100)$ & $16.9(201)^{c}$ & $42.9(33)^{\mathrm{c}}$ & $5.0(124)$ & $9.7(117)^{\mathrm{c}}$ & $24.6(93)^{c}$ & $3.5(116)$ & $25.7(188)^{\mathrm{c}}$ & $56.6(30)^{\mathrm{c}}$ \\
\hline No. of medications: mean (SD) & $1.6(2.0)$ & $2.8(2.7)^{\mathrm{c}}$ & $5.1(3.1)^{c}$ & $1.0(1.3)$ & $3.1(2.3)^{c}$ & $5.5(2.9)^{\mathrm{c}}$ & $1.7(2.0)$ & $3.4(3.0)^{\mathrm{c}}$ & $6.1(2.6)^{\mathrm{C}}$ \\
\hline Supplements: $\geq 1, \%$ (n) & $16.1(450)$ & $21.2(253)^{\mathrm{b}}$ & $22.1(17)$ & $12.6(311)$ & $24.6(298)^{c}$ & $29.4(111)^{c}$ & $16.4(539)$ & $22.7(166)^{c}$ & $28.3(15)^{\mathrm{a}}$ \\
\hline Disability: ADL/IADL $\geq 1, \%$ (n) & $4.2(117)$ & $14.5(173)^{\mathrm{c}}$ & $52.0(40)^{c}$ & $1.5(37)$ & $11.5(139)^{\mathrm{c}}$ & $40.7(154)^{c}$ & $4.7(153)$ & $19.7(144)^{\mathrm{c}}$ & $62.3(33)^{c}$ \\
\hline
\end{tabular}

CES-D, Center for Epidemiologic Studies Depression; CV, coefficients of variation; MMSE, Mini-Mental State Examination.

Significance is indicated by ${ }^{\mathrm{a}} \mathrm{P} \leq .05,{ }^{\mathrm{b}} \mathrm{P}<.01$, and ${ }^{\mathrm{c}} \mathrm{P}<.001$. 


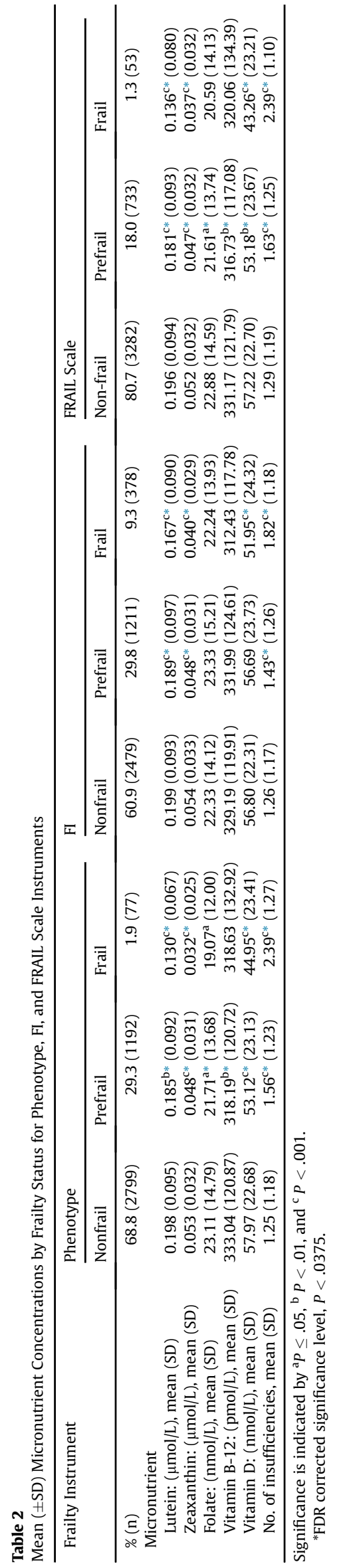

\section{Micronutrient Concentrations by Frailty Instrument and Status}

Differences in micronutrient concentrations by frailty status and instrument are provided in Table 2. Mean concentrations of lutein, zeaxanthin, and vitamin D were significantly, progressively, and consistently lower among the prefrail and frail groups across the phenotype, FI, and FRAIL instruments. Lower mean folate and vitamin B-12 were associated with prefrailty for the phenotype and FRAIL instruments only. The number of micronutrient insufficiencies present increased progressively and significantly with frailty status for all frailty instruments.

\section{Modelling of Associations Between Micronutrients and Frailty Instrument and Status}

Associations between transformed and standardized micronutrient measures and frailty status and instrument were modelled by unadjusted, minimally, and fully adjusted multinomial regression. Associations in unadjusted models for each frailty instrument (model 1) are presented in Supplementary Figure 1 and reflected those described for the untransformed nonstandardized micronutrient concentrations presented in Table 2. Differences remained significant at the FDR-adjusted level of $P<.0375$ as presented in Supplementary Figure 2.

In minimally adjusted models (model 2) as presented in Supplementary Figure 1 and Supplementary Table 3, a 1 SD increase in lutein was negatively associated with prefrailty [relative risk ratios (RRRs)]: 0.78-0.86) and frailty (RRRs: 0.43-0.63) for the 3 frailty instruments. Consistent negative associations with zeaxanthin and prefrailty (RRRs: $0.79-0.87$ ) and frailty (RRRs: $0.49-0.63$ ) were also observed. Higher Vitamin D was also negatively associated with prefrailty (RRRs: 0.80-0.82) and frailty (RRRs: 0.51-0.75), with the exception of the FI prefrail group. A 1 SD increase in folate was negatively associated with prefrailty (RRRs: 0.87-0.90) for the phenotype and FRAIL instruments only. The same pattern of association was observed for vitamin B-12 and prefrailty (RRRs: 0.91-0.92). Folate and vitamin B-12 were not associated with frailty for any instrument. The number of micronutrient insufficiencies present was significantly and progressively correlated with prefrailty (RRRs: 1.141.27 ) and frailty (RRRs: 1.42-1.90) for all frailty instruments. Differences remained significant at the FDR-adjusted level of $P<.0361$ as presented in Supplementary Figure 2.

In fully adjusted models (model 3 ) as presented in Table 3 and Supplementary Figure 1, a 1 SD increase in lutein (RRRs: 0.53-0.75), zeaxanthin (RRRs: 0.62-0.76), and vitamin D (RRRs: 0.50-0.73) remained negatively associated with frailty across all instruments. However, the pattern of associations was less consistent for prefrailty. A 1 SD increase in lutein was negatively associated with FI and FRAIL (RRRs: 0.87-0.88) but not phenotype prefrailty. Higher vitamin D levels were negatively associated with phenotype and FRAIL prefrailty (RRRs: 0.84-0.86) only, whereas higher zeaxanthin levels were negatively associated with FI prefrailty (RRR: 0.85 ) only. The number of micronutrient insufficiencies present remained significantly and progressively associated with prefrailty (RRRs: 1.10-1.17) and frailty (RRRs: 1.31-1.75) across instruments, except FI prefrailty. Differences remained significant at the FDR-adjusted level of $P<.0278$, as presented in Supplementary Figure 2.

\section{Discussion}

This study from a large representative sample of older adults demonstrated that lower levels of lutein, zeaxanthin, and vitamin D were associated 3 different measures of frailty, and that these relationships were present but weaker in measures of prefrailty. These results remained statistically significant following adjustment for 
Table 3

Fully Adjusted (Model 3) Associations Between Standardized Log Transformed Biomarkers and Frailty Status for Phenotype, FI, and FRAIL Scale Instruments

\begin{tabular}{|c|c|c|c|c|c|c|}
\hline \multirow[t]{3}{*}{ Micronutrient } & \multicolumn{2}{|l|}{ Phenotype } & \multicolumn{2}{|l|}{ Frailty Index } & \multicolumn{2}{|l|}{ FRAIL Scale } \\
\hline & Prefrail & Frail & Prefrail & Frail & Prefrail & Frail \\
\hline & RRR (95\% CI) & RRR (95\% CI) & RRR (95\% CI) & RRR (95\% CI) & RRR (95\% CI) & RRR (95\% CI) \\
\hline Lutein & $0.94(0.86-1.03)$ & $0.56^{\mathrm{c} *}(0.44-0.70)$ & $0.87^{\mathrm{b} *}(0.78-0.96)$ & $0.75^{\mathrm{c} *}(0.63-0.88)$ & $0.88^{\mathrm{a} *}(0.79-0.99)$ & $0.53^{\mathrm{c} *}(0.39-0.70)$ \\
\hline Zeaxanthin & $0.95(0.87-1.04)$ & $0.62^{\mathrm{b} *}(0.48-0.82)$ & $0.85^{\mathrm{b} *}(0.76-0.95)$ & $0.76^{\mathrm{b} *}(0.64-0.89)$ & $0.93(0.83-1.05)$ & $0.68^{\mathrm{a} *}(0.49-0.94)$ \\
\hline Folate & $0.92^{\dagger}(0.85-1.01)$ & $0.85(0.66-1.09)$ & $0.98(0.88-1.09)$ & $0.92(0.79-1.06)$ & $0.89^{\mathrm{a} *}(0.81-0.98)$ & $0.97(0.70-1.36)$ \\
\hline Vitamin B-12 & $0.95(0.87-1.03)$ & $1.11(0.82-1.51)$ & $1.02(0.92-1.14)$ & $1.02(0.85-1.21)$ & $0.94(0.85-1.04)$ & $1.27(0.86-1.88)$ \\
\hline Vitamin D & $0.84^{\mathrm{c} *}(0.77-0.92)$ & $0.65^{\mathrm{c} *}(0.51-0.82)$ & $0.91^{\dagger}(0.82-1.01)$ & $0.73^{\mathrm{c} *}(0.61-0.86)$ & $0.86^{\mathrm{b} *}(0.76-0.96)$ & $0.50^{\mathrm{c} *}(0.38-0.66)$ \\
\hline No. of Insufficiencies & $1.13^{\mathrm{b} *}(1.05-1.21)$ & $1.61^{\mathrm{c} *}(1.31-1.99)$ & $1.10^{\mathrm{a}}(1.01-1.21)$ & $1.31^{\mathrm{c} *}(1.15-1.48)$ & $1.17^{\mathrm{c} *}(1.08-1.27)$ & $1.75^{\mathrm{c} *}(1.34-2.29)$ \\
\hline
\end{tabular}

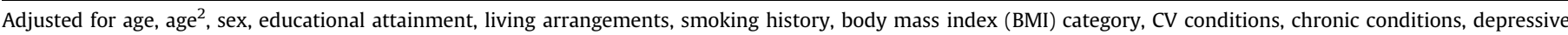
symptoms, global cognitive function, supplements (yes/no), and season when blood was drawn.

Significance is indicated by ${ }^{\mathrm{a}} P \leq .05,{ }^{\mathrm{b}} P<.01$, and ${ }^{\mathrm{c}} P<.001$.

*FDR-corrected significance level $P<.0278$.

'Significance is indicated by $P \leq .09$.

sociodemographic, lifestyle, health, and seasonal factors, and correcting for multiple testing. A relationship was not, however, observed between folate and vitamin B-12 and frailty and prefrailty, with the exception of 1 of the 12 comparisons studied.

For the carotenoids lutein and zeaxanthin, we report associations with both frailty and prefrailty in a large cohort of both men and women that build on the less representative findings of previous studies. Associations between total carotenoids and phenotype frailty were previously reported in over 700 women age $\geq 65$ years from the Women's Health and Aging Study. ${ }^{13,15}$ In a study of 4731 adults age $\geq 60$ years from the National Health and Nutrition Examination Survey (NHANES) III, levels of total carotenoids were associated with a 4-item phenotype frailty instrument. ${ }^{40}$ Lutein and zeaxanthin are xanthophyll carotenoids obtained from egg yolk, orange/yellow, leafy green vegetables, and fruits. ${ }^{56}$ These carotenoids are found in the protective macular pigment of the eye, in circulation, and in the brain, and correlate with cognitive function. ${ }^{57}$ They act as efficient antioxidants and anti-inflammatory compound ${ }^{25,58}$ with a putative protective role in chronic diseases of aging including cancer, cardiovascular disease, diabetes, neurodegenerative disease, and bone health. ${ }^{19-23}$ Thus, carotenoid deficiency contributes to chronic disease across multiple physiological systems a central feature of frailty.

Evidence supporting an association between frailty and folate or vitamin B-12 is equivocal. Markers of vitamin B deficiency were previously associated with phenotype frailty in the Women's Health and Aging Study, ${ }^{15,39}$ but in the NHANES III study no association was reported for either folate or vitamin B-12. ${ }^{40}$ Our data suggests a correlation with prefrailty for the phenotype and FRAIL measures. The lack of association with frailty may result from the smaller numbers in these frail groups. It should also be noted that dietary supplement use was significantly higher among those with prefrailty and frailty (Table 1) and may have masked the associations between B vitamins and frailty. This may indicate dietary supplementation of older adults with frailty or multimorbidity by primary care physicians in the community. We recently reported that deficient/low status for folate and vitamin B-12 are prevalent in Ireland, 15\% and 12\%, respectively, compared with countries with mandatory fortification policies. ${ }^{59}$ Low folate and folate/vitamin B-12 imbalance impairs DNA synthesis/ repair and methylation, cellular regulation processes, and amino acid metabolism. ${ }^{28}$ Low folate status is also linked to higher rates of cognitive impairment, cardiovascular disease, and cancer mortality. ${ }^{60-62}$ Undiagnosed vitamin B-12 deficiency can cause irreversible neurologic damage over time. ${ }^{63}$ The role of low folate and vitamin B12 in frailty is likely mediated via impaired maintenance of cellular homeostasis leading to cardiovascular and neurocognitive manifestations, both common features of frailty. ${ }^{28-31}$

Our findings support an association between lower levels of vitamin D and frailty, which is documented in the literature. $^{13,41-46,64,65}$ One study of 3968 adults from NHANES III demonstrated that vitamin $D$ deficiency was associated with a 3.7-fold increased odds of frailty adjusting for season and latitude. ${ }^{64}$ We provide evidence for an association with prefrailty, which is less well reported. Vitamin D insufficiency affects $40 \%$ of older Irish adults ${ }^{54}$ and is implicated in the risk of negative outcomes for musculoskeletal health and falls prevention. ${ }^{32,66}$ Vitamin D levels among older adults are negatively impacted by reductions in UVB exposure, endogenous synthesis, dietary intake, and age-related malabsorption. Low vitamin D reduces calcium absorption and increases parathyroid hormone leading to increased risk of fracture. ${ }^{67}$ In addition, low vitamin D (coupled with age-related decreases in vitamin D receptor density) may contribute to reduced protein synthesis and immunomodulating effects on the immune and wider organ-tissue system. This in turn leads to poor musculoskeletal, cardiovascular, and immune function, which are hallmarks of frailty. ${ }^{33,35,68}$

Our finding that both prefrailty and frailty are progressively associated with accumulation of micronutrient insufficiencies in this large cohort of older adults builds on less representative studies that used 1 frailty measure only. ${ }^{8,11,37}$ Micronutrient insufficiencies may impact on frailty via multiple dysregulated pathways including DNA synthesis, protein biosynthesis, mitochondrial function, and cell regulation processes. ${ }^{28}$ This results in an oxidative cellular environment that promotes inflammatory and stress responses, leading to impaired cell function and senescence. ${ }^{69}$ Over time cellular dysregulation eventually manifests at the organ and system level as the functional impairments we commonly associate with frailty. ${ }^{70}$

Vitamin D and the B-vitamins are routinely measured in clinical laboratories and have validated recommended dietary reference intakes and clinical biomarker cut-offs for insufficiency and deficiency. Support for lutein (and zeaxanthin) to receive recommended dietary reference intakes from the National Academies of Sciences, Engineering and Medicine is growing, and are likely to be forthcoming in the near future based on the Lupton criteria. ${ }^{24,71,72}$ Lutein content in foods and tissues is commonly analyzed and quantified via highperformance liquid chromatography. The National Institute of Standards and Technology developed standard reference material 968e, which includes lutein among other carotenoids, fat-soluble vitamins, and cholesterol in human serum. ${ }^{73}$ Measuring panels of these micronutrients, rather than individual micronutrients, will provide greater accuracy for identifying older adults at risk of nutritional as well as physical frailty.

Strengths of this study include the large representative sample of adults age $\geq 50$ years, measurement of micronutrients using gold standard laboratory methodologies, use of 3 widely accepted frailty instruments, and implementation of multiple test correction. Limitations include the inconsistency of associations between micronutrients and prefrailty across instruments. This may result from 
insufficient power to detect smaller effect sizes for prefrailty, the subclinical heterogenous and prodromic nature of prefrailty, and confounding by factors not included in our models. Finally, we acknowledge that the cross-sectional nature of this study precludes us from drawing any conclusions regarding causality, which may be undertaken using subsequent waves of TILDA data.

\section{Conclusions and Implications}

In conclusion, we have presented the most consistent evidence in the largest study to date that lower levels of specific micronutrients-lutein, zeaxanthin, and vitamin D-are progressively associated with prefrailty and frailty using 3 commonly utilized frailty instruments. We also demonstrated that the accumulation of micronutrient insufficiencies was associated with prefrailty and frailty across these instruments. Our data suggest that low micronutrient status may act as an easily modified marker and intervention target for frailty among adults age $\geq 50$ years. Micronutrient supplementation and mandatory food fortification may be cost-effective strategies to both prevent and intervene in the progression of frailty. If our findings are confirmed by ongoing research studies internationally, delays in implementing such policies may represent a missed opportunity to preserve function and increase healthy life years by ameliorating frailty and disability risk in older adults.

\section{Acknowledgments}

We are grateful to all of the TILDA respondents for participating in the study. Researchers interested in using TILDA data may access the data for free from the following sites: Irish Social Science Data Archive at University College Dublin http://www.ucd.ie/issda/data/tilda/or the Interuniversity Consortium for Political and Social Research (ICPSR) at the University of Michigan http://www.icpsr.umich.edu/icpsrweb/ ICPSR/studies/34315.

\section{References}

1. Clegg A, Young J, Iliffe S, et al. Frailty in elderly people. Lancet 2013;381(9868): $752-762$.

2. Crome P, Lally F. Frailty: joining the giants. CMAJ 2011;183(8):889-890.

3. Van Craen K, Braes T, Wellens N, et al. The effectiveness of inpatient geriatric evaluation and management units: a systematic review and meta-analysis. J Am Geriatr Soc 2010;58(1):83-92.

4. Fried LP, Tangen CM, Walston J, et al. Frailty in older adults: evidence for a phenotype. J Gerontol A Biol Sci Med Sci 2001;56(3):M146-M156.

5. Mitnitski AB, Song X, Rockwood K. The estimation of relative fitness and frailty in community-dwelling older adults using self-report data. J Gerontol A Biol Sci Med Sci 2004;59(6):M627-M632.

6. Morley JE, Malmstrom TK, Miller DK. A simple frailty questionnaire (FRAIL) predicts outcomes in middle aged African Americans. J Nutr Health Aging 2012; 16(7):601-608.

7. Collard RM, Boter H, Schoevers RA, Oude Voshaar RC. Prevalence of frailty in community-dwelling older persons: a systematic review. J Am Geriatr Soc 2012;60(8):1487-1492.

8. Lee JS, Auyeung TW, Leung J, et al. Transitions in frailty states among community-living older adults and their associated factors. J Am Med Dir Assoc 2014;15(4):281-286.

9. Ames BN, Shigenaga MK, Hagen TM. Oxidants, antioxidants, and the degenerative diseases of aging. Proc Natl Acad Sci U S A 1993;90(17):7915-7922.

10. Fairfield KM, Fletcher RH. Vitamins for chronic disease prevention in adults: scientific review. JAMA 2002;287(23):3116-3126.

11. High KP. Micronutrient supplementation and immune function in the elderly. Clin Infect Dis 1999;28(4):717-722.

12. Lane JS, Magno CP, Lane KT, et al. Nutrition impacts the prevalence of peripheral arterial disease in the United States. J Vasc Surg 2008;48(4):897-904.

13. Michelon E, Blaum C, Semba RD, et al. Vitamin and carotenoid status in older women: associations with the frailty syndrome. J Gerontol A Biol Sci Med Sci 2006;61(6):600-607.

14. Rizzoli R. Management of the oldest old with osteoporosis. Eur Geriatr Med 2010;1(1):15-21.

15. Semba RD, Bartali B, Zhou J, et al. Low serum micronutrient concentrations predict frailty among older women living in the community. J Gerontol A Biol Sci Med Sci 2006;61(6):594-599.
16. Kelaiditi E, Guyonnet S, Cesari M. Is nutrition important to postpone frailty? Curr Opin Clin Nutr Metab Care 2015;18(1):37-42.

17. Malafarina V, Uriz-Otano F, Gil-Guerrero L, Iniesta R. The anorexia of ageing physiopathology, prevalence, associated comorbidity and mortality. A systematic review. Maturitas 2013;74(4):293-302.

18. Remond D, Shahar DR, Gille D, et al. Understanding the gastrointestinal tract of the elderly to develop dietary solutions that prevent malnutrition. Oncotarget 2015;6(16):13858-13898.

19. Leoncini E, Nedovic D, Panic N, et al. Carotenoid Intake from Natural Sources and Head and Neck Cancer: A Systematic Review and Meta-analysis of Epidemiological Studies. Cancer Epidemiol Biomarkers Prev 2015;24(7): 1003-1011.

20. Hak AE, Stampfer MJ, Campos H, et al. Plasma carotenoids and tocopherols and risk of myocardial infarction in a low-risk population of US male physicians. Circulation 2003;108(7):802-807.

21. Hamer M, Chida Y. Intake of fruit, vegetables, and antioxidants and risk of type 2 diabetes: systematic review and meta-analysis. J Hypertens 2007;25(12): 2361-2369.

22. Amadieu C, Lefevre-Arbogast S, Delcourt C, et al. Nutrient biomarker patterns and long-term risk of dementia in older adults. Alzheimers Dement 2017; 13(10): 1125-1132.

23. Sugiura M, Nakamura M, Ogawa K, et al. High serum carotenoids associated with lower risk for bone loss and osteoporosis in post-menopausal Japanese female subjects: prospective cohort study. PLoS One 2012;7(12):e52643.

24. Bohn T. Carotenoids, Chronic Disease Prevention and Dietary Recommendations. Int J Vitam Nutr Res 2017;87(3-4):121-130.

25. Ben-Dor A, Steiner M, Gheber L, et al. Carotenoids activate the antioxidant response element transcription system. Mol Cancer Ther 2005;4(1):177-186.

26. Palozza P, Simone R, Catalano A, et al. Lycopene prevention of oxysterolinduced proinflammatory cytokine cascade in human macrophages: inhibition of NF-kappaB nuclear binding and increase in PPARgamma expression. J Nutr Biochem 2011;22(3):259-268.

27. Gruszecki WI, Strzalka K. Carotenoids as modulators of lipid membrane physical properties. Biochim Biophys Acta 2005;1740(2):108-115.

28. Kennedy DO. B Vitamins and the Brain: Mechanisms, Dose and Efficacy-A Review. Nutrients 2016;8(2):68.

29. Bailey LB. Folate in health and disease. 2nd edition. USA: CRC press; 2017.

30. Stover PJ. Physiology of folate and vitamin B12 in health and disease. Nutr Rev 2004;62(6 Pt 2):S3-S12. discussion S13.

31. Strickland KC, Krupenko NI, Krupenko SA. Molecular mechanisms underlying the potentially adverse effects of folate. Clin Chem Lab Med 2013;51(3): 607-616.

32. Institue of Medicine (United States). Dietary Reference Intakes for Calcium and Vitamin D. Washington, DC: National Academies Press; 2011.

33. Pludowski P, Holick MF, Pilz S, et al. Vitamin D effects on musculoskeletal health, immunity, autoimmunity, cardiovascular disease, cancer, fertility, pregnancy, dementia and mortality-a review of recent evidence. Autoimmun Rev 2013;12(10):976-989.

34. Skaaby T. The relationship of vitamin D status to risk of cardiovascular disease and mortality. Dan Med J 2015;62(2). pii: B5008. Review.

35. Haussler MR, Whitfield GK, Kaneko I, et al. Molecular mechanisms of vitamin D action. Calcif Tissue Int 2013;92(2):77-98.

36. Krishnan AV, Feldman D. Mechanisms of the anti-cancer and anti-inflammatory actions of vitamin D. Annu Rev Pharmacol Toxicol 2011:51:311-336.

37. Bartali B, Frongillo EA, Bandinelli S, et al. Low nutrient intake is an essential component of frailty in older persons. J Gerontol A Biol Sci Med Sci 2006;61(6): 589-593.

38. Kobayashi S, Asakura K, Suga H, et al. Inverse association between dietary habits with high total antioxidant capacity and prevalence of frailty among elderly Japanese women: a multicenter cross-sectional study. J Nutr Health Aging 2014;18(9):827-839.

39. Matteini AM, Walston JD, Fallin MD, et al. Markers of B-vitamin deficiency and frailty in older women. J Nutr Health Aging 2008;12(5):303-308.

40. Smit E, Winters-Stone KM, Loprinzi PD, et al. Lower nutritional status and higher food insufficiency in frail older US adults. Br J Nutr 2013;110(1): $172-178$.

41. Buta B, Choudhury PP, Xue OL, et al. The Association of Vitamin D Deficiency and Incident Frailty in Older Women: The Role of Cardiometabolic Diseases. J Am Geriatr Soc 2017;65(3):619-624.

42. Ensrud KE, Blackwell TL, Cauley JA, et al. Circulating 25-hydroxyvitamin D levels and frailty in older men: the osteoporotic fractures in men study. J Am Geriatr Soc 2011;59(1):101-106.

43. Ensrud KE, Ewing SK, Fredman L, et al. Circulating 25-hydroxyvitamin D levels and frailty status in older women. J Clin Endocrinol Metab 2010;95(12): 5266-5273.

44. Puts MT, Visser M, Twisk JW, et al. Endocrine and inflammatory markers as predictors of frailty. Clin Endocrinol (Oxf) 2005;63(4):403-411.

45. Vogt S, Decke S, de Las Heras Gala T, et al. Prospective association of vitamin D with frailty status and all-cause mortality in older adults: Results from the KORA-Age Study. Prev Med 2015;73:40-46.

46. Wong YY, McCaul KA, Yeap BB, et al. Low vitamin D status is an independent predictor of increased frailty and all-cause mortality in older men: the Health in Men Study. J Clin Endocrinol Metab 2013:98(9):3821-3828.

47. Kearney PM, Cronin H, O'Regan C, et al. Cohort profile: the Irish Longitudinal Study on Ageing. Int J Epidemiol 2011;40(4):877-884. 
48. Whelan BJ, Savva GM. Design and methodology of the Irish Longitudinal Study on Ageing. J Am Geriatr Soc 2013;61(Suppl 2):S265-S268.

49. Roe L, Normand C, Wren MA, et al. The impact of frailty on healthcare utilisation in Ireland: evidence from the Irish longitudinal study on ageing. BMC Geriatr 2017;17(1):203.

50. Moran R, Nolan JM, Stack J, et al. Non-Dietary Correlates and Determinants of Plasma Lutein and Zeaxanthin Concentrations in the Irish Population. J Nutr Health Aging 2017;21(3):254-261.

51. Nolan JM, Loskutova E, Howard AN, et al. Macular pigment, visual function, and macular disease among subjects with Alzheimer's disease: an exploratory study. J Alzheimers Dis 2014;42(4):1191-1202.

52. Molloy AM, Scott JM. Microbiological assay for serum, plasma, and red cell folate using cryopreserved, microtiter plate method. Methods Enzymol 1997 281:43-53.

53. Kelleher BP, Broin SD. Microbiological assay for vitamin B12 performed in 96well microtitre plates. J Clin Pathol 1991;44(7):592-595.

54. Laird E, O'Halloran AM, Carey D, et al. The Prevalence of Vitamin D Deficiency and the Determinants of 25(OH)D Concentration in Older Irish Adults: Data From The Irish Longitudinal Study on Ageing (TILDA). J Gerontol A Biol Sci Med Sci 2018;73(4):519-525.

55. Benjamini Y, Hochberg Y. Controlling the False Discovery Rate: A Practical and Powerful Approach to Multiple Testing; 1995. p. 289-300.

56. Hammond BR Jr, Renzi LM. Carotenoids. Adv Nutr 2013;4(4):474-476.

57. Feeney J, O'Leary N, Moran R, et al. Plasma Lutein and Zeaxanthin Are Associated With Better Cognitive Function Across Multiple Domains in a Large Population-Based Sample of Older Adults: Findings from The Irish Longitudina Study on Aging. J Gerontol A Biol Sci Med Sci 2017;72(10):1431-1436.

58. Yeum KJ, Beretta G, Krinsky NI, et al. Synergistic interactions of antioxidant nutrients in a biological model system. Nutrition 2009;25(7-8):839-846.

59. Laird EJ, O'Halloran AM, Carey D, et al. Voluntary fortification is ineffective to maintain the vitamin B12 and folate status of older Irish adults: evidence from the Irish Longitudinal Study on Ageing (TILDA). Br J Nutr 2018;120(1): $111-120$.

60. Koike H, Takahashi M, Ohyama K, et al. Clinicopathologic features of folatedeficiency neuropathy. Neurology 2015;84(10):1026-1033.
61. Peng Y, Dong B, Wang Z. Serum folate concentrations and all-cause, cardiovascular disease and cancer mortality: A cohort study based on 1999-2010 National Health and Nutrition Examination Survey (NHANES). Int J Cardiol 2016:219:136-142.

62. Vogel T, Dali-Youcef N, Kaltenbach G, Andres E. Homocysteine, vitamin B12, folate and cognitive functions: a systematic and critical review of the literature. Int J Clin Pract 2009;63(7):1061-1067.

63. Stabler SP. Clinical practice. Vitamin B12 deficiency. N Engl J Med 2013;368(2): 149-160.

64. Wilhelm-Leen ER, Hall YN, Deboer IH, Chertow GM. Vitamin D deficiency and frailty in older Americans. J Intern Med 2010;268(2):171-180.

65. Zhou J, Huang P, Liu P, et al. Association of vitamin D deficiency and frailty: A systematic review and meta-analysis. Maturitas 2016;94:70-76.

66. SACN (Scientific Advisory Committee on Nutrition). Report on Vitamin D and Health. London: Public Health England; Crown; 2016.

67. Visser M, Deeg DJ, Lips P, Longitudinal Aging Study A. Low vitamin D and high parathyroid hormone levels as determinants of loss of muscle strength and muscle mass (sarcopenia): the Longitudinal Aging Study Amsterdam. J Clin Endocrinol Metab 2003;88(12):5766-5772.

68. Bischoff HA, Borchers M, Gudat F, et al. In situ detection of 1,25-dihydroxyvitamin D3 receptor in human skeletal muscle tissue. Histochem J 2001;33(1): 19-24.

69. Wilson D, Jackson T, Sapey E, Lord JM. Frailty and sarcopenia: The potential role of an aged immune system. Ageing Res Rev 2017;36:1-10.

70. Tan BL, Norhaizan ME, Liew WP, Sulaiman Rahman H. Antioxidant and Oxidative Stress: A Mutual Interplay in Age-Related Diseases. Front Pharmacol 2018;9:1162.

71. Lupton JR, Atkinson SA, Chang N, et al. Exploring the benefits and challenges of establishing a DRI-like process for bioactives. Eur J Nutr 2014;53(Suppl 1):1-9.

72. Ranard KM, Jeon S, Mohn ES, et al. Dietary guidance for lutein: consideration for intake recommendations is scientifically supported. Eur J Nutr 2017;56(Suppl 3):37-42.

73. Thomas JB, Duewer DL, Mugenya IO, et al. Preparation and value assignment of standard reference material 968e fat-soluble vitamins, carotenoids, and cholesterol in human serum. Anal Bioanal Chem 2012;402(2):749-762. 
Supplementary Material 1. Description of Frailty Outcome Variables Operationalized in the TILDA Database Using a computer-aided Personal Interview and Health Assessment Data

FRIED phenotype: Operationalized using TILDA populationspecific cut-points following the methodology of Fried et al. ${ }^{1,2}$

Weakness: Sex- and body mass index-adjusted grip-strength measured on the dominant hand using baseline dynamometer. Weight and height was measured using standardized procedures during home and health center assessments.

Physical activity: Sex-adjusted kilocalories (kcals) from the International Physical Activity Questionnaire-Short Form [IPAQ-SF]).

Slow walking speed: Sex- and height-adjusted time taken in seconds to perform the Timed Up-and-Go (TUG) task.

Unintended Weight loss: was ascertained by the question "In the past year have you lost 10 pounds $(4.5 \mathrm{~kg}$ ) or more in weight when you were not trying to."

Exhaustion: was captured using two items from the 20-item Center for Epidemiological Studies Depression (CES-D) scale. Participants were asked how often they felt that "I could not get going" and "I felt that everything I did was an effort". A response of "moderate amount/ all of the time" to either question was considered as "exhaustion."

The categorical cut-points were: 0 : Robust, $1-2$ : Prefrail and $\geq 3$ : Frail.

FI: 32 deficits based on self-reported measures from TILDA computer-aided personal interview questionnaire.

A deficit accumulation FI was constructed using 32 self-reported health deficits from the TILDA home interview following the previously published methodology. The 32 deficits were associated with poor health, were distributed across several health domains and were associated with advancing age. Dichotomous deficits were coded as present (1) or absent (0). Ordered categorical deficits were coded as a fraction proportional to the number of responses (eg, 5 categories from none to all of a deficit was coded as $0,0.25,0.5,0.75,1.0$ ). The total was then summed and divided by 32 . This produced index scores between 0.0 and 1.0. The 32 deficits included in the FI are listed in Supplementary Table 1 . Scores of $<0.10, \geq 0.10$ to $<0.25$ and $\geq 0.25$ were classified as nonfrail, prefrail, and frail, respectively.

Details of questionnaires and derived variables are available at http://www.ucd.ie/issda/static/documentation/tilda/tilda-capi-qairewave1.pdf and https://www.ucd.ie/t4cms/Derived\%20Variables\%20C odebook_\%20wave\%201\%20v1.6.docx.
FRAIL scale: Five criteria adapted from the published model by Morley et $\mathrm{al}^{6}$ based on self-reported measures from TILDA computeraided personal interview questionnaire data. Variables included:

Fatigue: How much of the time during the past 4 weeks did you feel tired?

Resistance: By yourself and not using aids, do you have any difficulty walking up one flight of stairs without resting?

Ambulation: By yourself and not using aids, do you have any difficulty walking several hundred yards?

Illnesses: $\geq 5$ of the following conditions: cancer, heart attack, heart failure, stroke, diabetes, high blood pressure, high cholesterol, cataracts, arthritis, osteoporosis, lung disease, asthma, Parkinson's disease, hip fracture, and varicose ulcer.

Loss of weight: In the past year have you lost 10 pounds $(4.5 \mathrm{~kg})$ or more in weight when you were not trying to?

The categorical cut-points were: 0 : Robust, $1-2$ : Prefrail and $\geq 3$ : Frail.

\section{Supplementary Material 2. Brief Description of Micronutrient Biomarkers Analyzed}

The carotenoids lutein and zeaxanthin were measured by reversed phase high performance liquid chromatography method at the Macular Pigment Research Group, Waterford Institute of Technology. Details of extraction procedures and high performance liquid chromatography analysis were previously described. ${ }^{3,4}$ The detection ranges of the analyzed samples were $0.01-2.69 \mu \mathrm{mol} / \mathrm{L}$ and $0.002-0.83 \mu \mathrm{mol} / \mathrm{L}$ for lutein and zeaxanthin respectively. Average inter-assay coefficients of variation (CV) were $4.0 \%$ and $6.8 \%$, respectively.

Total plasma vitamin B-12 (cobalamin) and folate concentrations were determined by microbiological assays as previously described. ${ }^{5,6}$ The detection ranges of the analyzed samples for vitamin B-12 and folate were 45.4-1941.4 pmol/L and 0.9-642.2 nmol/L, respectively. The inter-assay CVs for vitamin B-12 and folate were $<10.9 \%$.

Plasma 25-hydroxyvitamin D $(25(\mathrm{OH}) \mathrm{D})$ concentrations were quantified by a fully validated method using MassChrom 25-OHVitamin D3/D2 (Chromsystems Instruments and Chemicals GmbH, Gräfelfing-Munich, Germany) using liquid chromatographytandem mass spectrometry (API 4000; AB SCIEX, Warrington, UK) as described previously. ${ }^{7}$ The detection range of the analyzed samples for 25(OH)D was determined to be $2.1-510.0 \mathrm{nmol} / \mathrm{L}$ and the average inter-assay CV was $5.7 \%$. 
Model 1

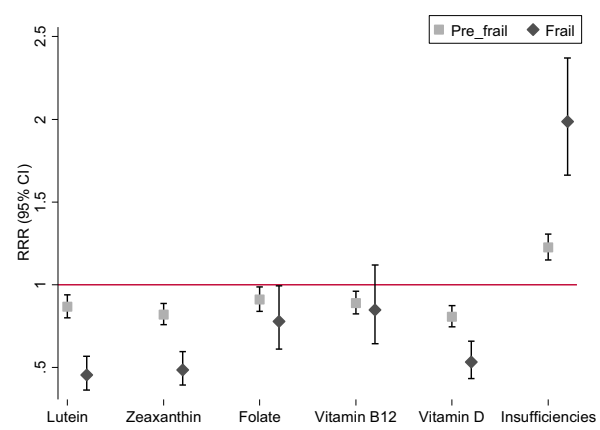

Model 1

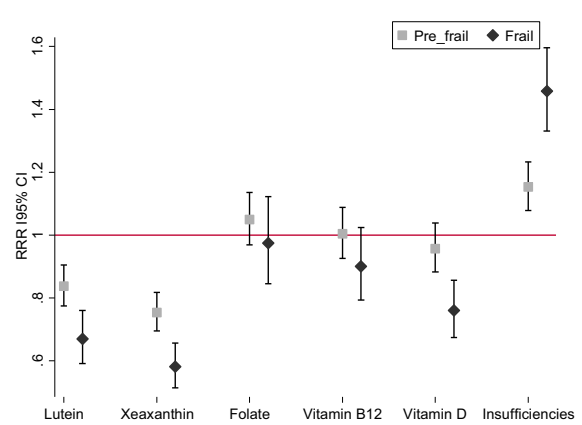

Model 1

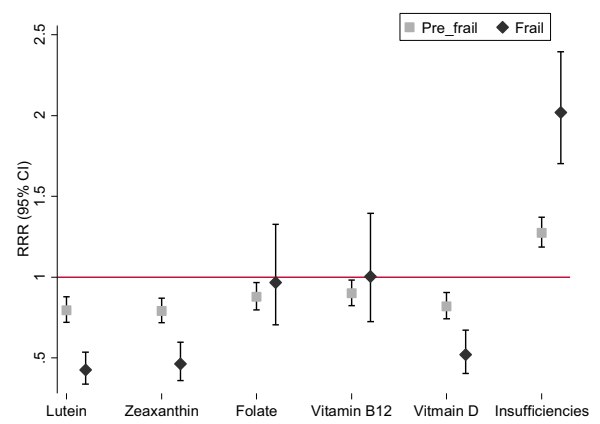

Phenotype

Model 2
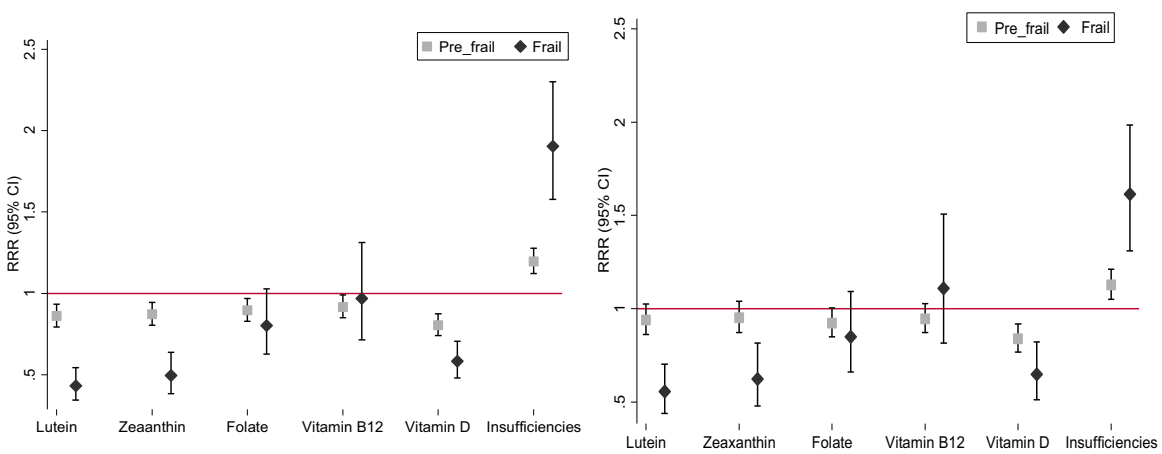

Frailty Index (FI)

Model 2

Model 3
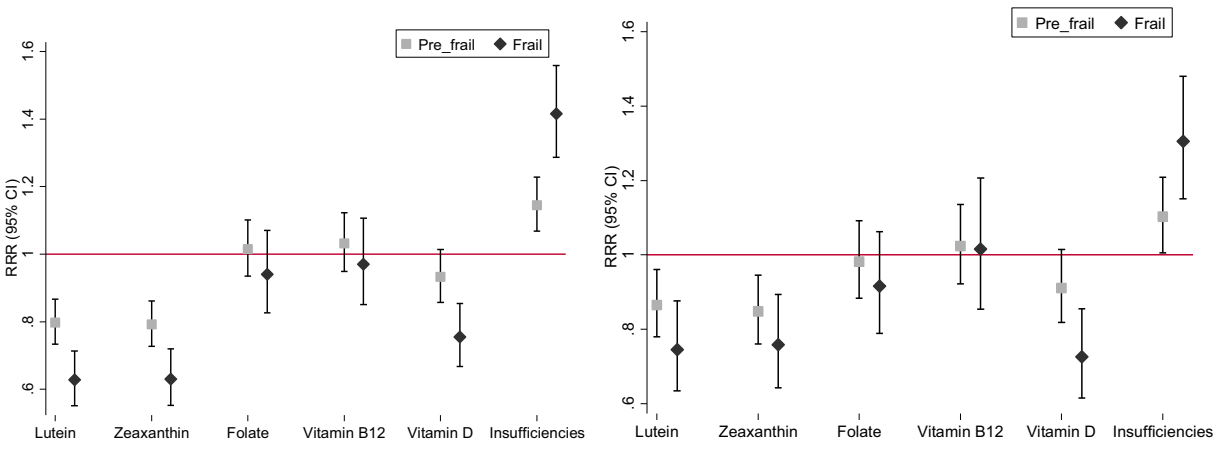

FRAILScale

Model 2

Model 3

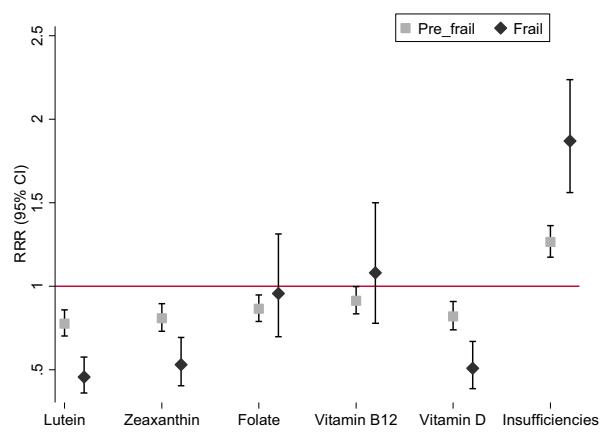

$\square$ Pre_frail $\bullet$ Frail

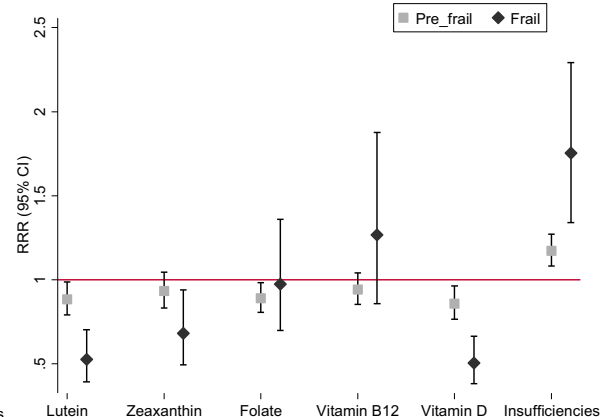

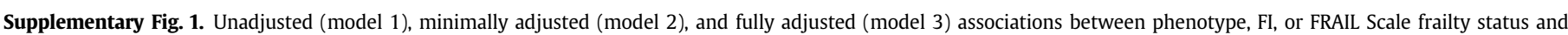
micronutrient biomarkers. Associations are measured by RRR with 95\% confidence Intervals (95\% CIs). 


\section{Model 1}

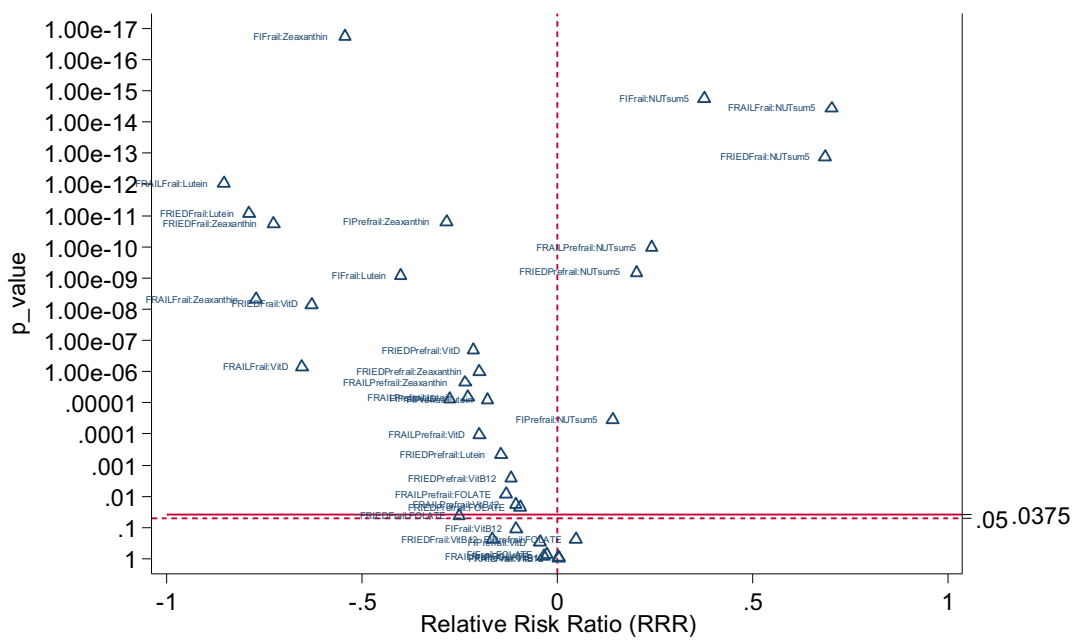

Model 2

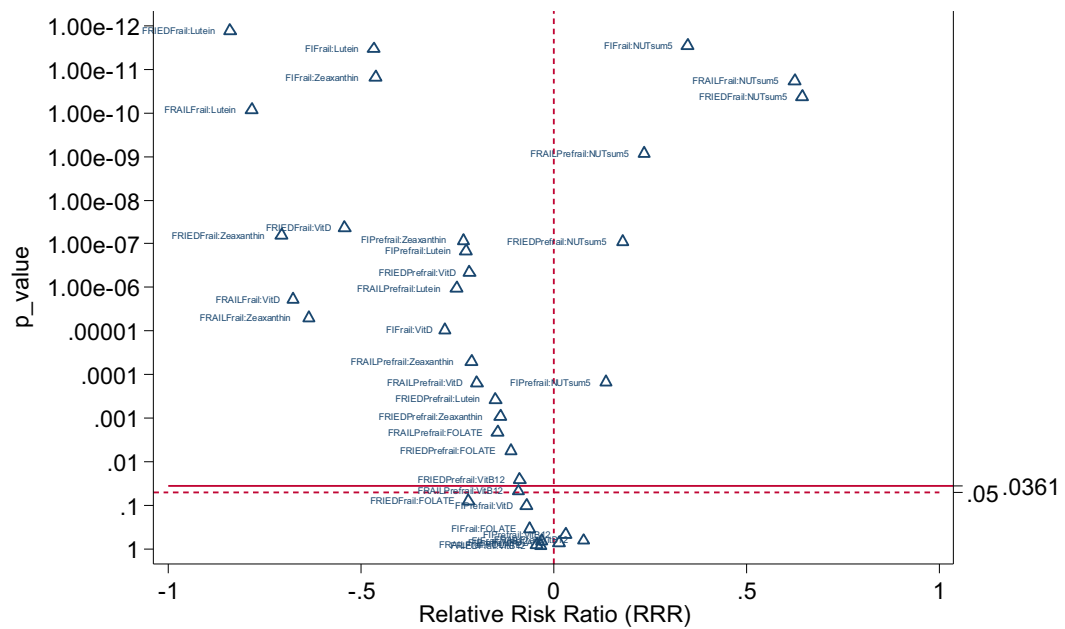

Model 3

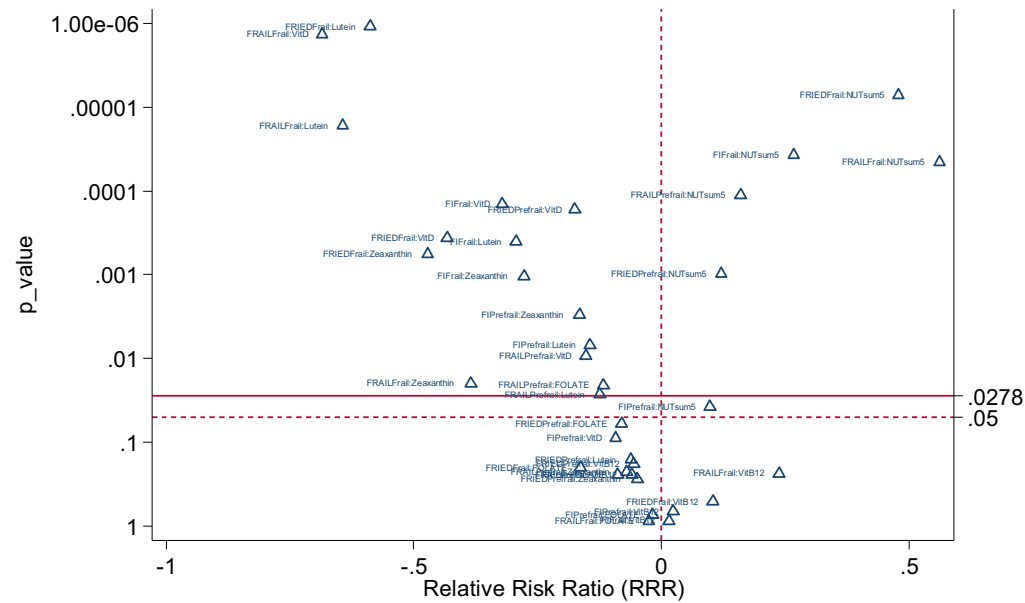

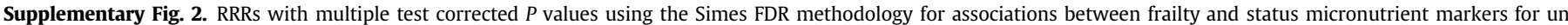
adjusted (model 1), minimally (model 2), and fully (model 3) adjusted models. 
Supplementary Table 1

The 32 deficits included in the Frailty Index (FI)

\begin{tabular}{|c|c|}
\hline Variables in TILDA & Cut-points \\
\hline 1. Difficulty walking $100 \mathrm{~m}$ & Yes $=1 ;$ No $=0$ \\
\hline 2. Difficulty rising from chair & Yes $=1 ;$ No $=0$ \\
\hline $\begin{array}{l}\text { 3. Difficulty climbing } 1 \text { flight of } \\
\text { stairs }\end{array}$ & Yes $=1 ;$ No $=0$ \\
\hline $\begin{array}{l}\text { 4. Difficulty stooping, kneeling, or } \\
\text { crouching }\end{array}$ & Yes $=1 ;$ No $=0$ \\
\hline $\begin{array}{l}\text { 5. Difficulty reaching above } \\
\text { shoulder height }\end{array}$ & Yes $=1 ;$ No $=0$ \\
\hline $\begin{array}{l}\text { 6. Difficulty pushing/pulling large } \\
\text { objects }\end{array}$ & Yes $=1 ;$ No $=0$ \\
\hline $\begin{array}{l}\text { 7. Difficulty lifting/carrying weights } \\
\geq 10 \mathrm{lb}\end{array}$ & Yes $=1 ;$ No $=0$ \\
\hline $\begin{array}{l}\text { 8. Difficulty picking up coin from } \\
\text { table }\end{array}$ & Yes $=1 ;$ No $=0$ \\
\hline 9. Feeling lonely & $\begin{array}{l}\text { Rarely or none of the time }=0 ; \\
\text { Some or a little of the time }=0.33 \text {; } \\
\text { Occasionally or a moderate amount } \\
\text { of time }=0.66 ; \\
\text { All of the time }(5-7 \mathrm{~d})=1\end{array}$ \\
\hline 10. Poor self-rated physical health & $\begin{array}{l}\text { Excellent }=0 ; \text { Very good }=0.25 \\
\quad \text { Good }=0.5 ; \\
\text { Fair }=0.75 ; \text { Poor }=1\end{array}$ \\
\hline 11. Poor self-rated vision & $\begin{array}{l}\text { Excellent }=0 ; \text { Very good }=0.25 \\
\quad \text { Good }=0.5 ; \\
\text { Fair }=0.75 ; \text { Poor }=1\end{array}$ \\
\hline 12. Poor self-rated hearing & $\begin{array}{l}\text { Excellent }=0 ; \text { Very good }=0.25 \\
\quad \text { Good }=0.5 ; \\
\text { Fair }=0.75 ; \text { Poor }=1\end{array}$ \\
\hline 13. Poor self-rated memory & $\begin{array}{l}\text { Excellent }=0 \text {; Very good }=0.25 \text {; } \\
\quad \text { Good }=0.5 ; \\
\text { Fair }=0.75 ; \text { Poor }=1\end{array}$ \\
\hline $\begin{array}{l}\text { 14. Difficulty following a } \\
\text { conversation with one person }\end{array}$ & $\begin{array}{l}\text { None }=0 ; \text { Some }=0.5 ; \text { Much } / \\
\quad \text { Impossible }=1\end{array}$ \\
\hline 15. Daytime sleepiness & $\begin{array}{l}\text { Would never doze }=0 ; \\
\text { Slight chance of dozing }=0.33 ; \\
\text { Moderate chance of dozing }=0.66 \text {; } \\
\text { High chance of dozing }=1\end{array}$ \\
\hline 16. Polypharmacy ( $\geq 5$ medications) & $\mathrm{Yes}=1 ; \mathrm{No}=0$ \\
\hline 17. Knee pain & Yes $=1 ;$ No $=0$ \\
\hline $\begin{array}{l}\text { 18. Hypertension or high blood } \\
\text { pressure }\end{array}$ & Yes $=1 ;$ No $=0$ \\
\hline 19. Angina & Yes $=1 ;$ No $=0$ \\
\hline 20. Heart attack & Yes $=1 ; \mathrm{No}=0$ \\
\hline 21. Diabetes & Yes $=1 ;$ No $=0$ \\
\hline $\begin{array}{l}\text { 22. Stroke and Transient ischemic } \\
\text { attack }\end{array}$ & Yes $=1 ;$ No $=0$ \\
\hline 23. High cholesterol & Yes $=1 ;$ No $=0$ \\
\hline 24. Irregular heart rhythm & Yes $=1 ;$ No $=0$ \\
\hline 25. Other cardiovascular disease & Yes $=1 ;$ No $=0$ \\
\hline 26. Cataracts & Yes $=1 ;$ No $=0$ \\
\hline $\begin{array}{l}\text { 27. Glaucoma and age-related } \\
\text { macular degeneration }\end{array}$ & Yes $=1 ;$ No $=0$ \\
\hline 28. Arthritis & Yes $=1 ;$ No $=0$ \\
\hline 29. Osteoporosis & Yes $=1 ;$ No $=0$ \\
\hline 30. Cancer & Yes $=1 ;$ No $=0$ \\
\hline 31. Varicose ulcer & Yes $=1 ;$ No $=0$ \\
\hline 32. Urinary incontinence & Yes $=1 ;$ No $=0$ \\
\hline
\end{tabular}

Supplementary Table 2

Characteristics of Analytic and Excluded Samples at Wave 1 of TILDA

\begin{tabular}{|c|c|c|c|}
\hline Characteristics & Category & $\begin{array}{l}\text { Analysis } \\
\text { Sample }\end{array}$ & Excluded \\
\hline & $\%(n)$ & $49.8(4068)$ & $50.2(4,107)$ \\
\hline \multirow[t]{4}{*}{ Age: $y$} & mean $(\mathrm{SD})$ & $61.7(8.3)$ & $66.0(10.6)^{\mathrm{c}}$ \\
\hline & $\geq 50 y, \%(n)$ & $49.8(4068)$ & $50.2(4,104)^{c}$ \\
\hline & $\geq 65 \mathrm{y}, \%(\mathrm{n})$ & $44.3(1413)$ & $59.7(2091)^{c}$ \\
\hline & $\geq 75 \mathrm{y}, \%(\mathrm{n})$ & $25.4(341)$ & $74.6(1,003)^{c}$ \\
\hline \multirow[t]{2}{*}{ Sex } & Male, \% (n) & $47.9(1974)$ & $43.8(1,799)$ \\
\hline & Female, \% (n) & $52.1(2121)$ & $56.2(2,308)^{c}$ \\
\hline \multirow[t]{3}{*}{ Education } & Primary, \% (n) & $22.1(897)$ & $39.1(1,606)$ \\
\hline & Secondary, \% (n) & $42.3(1720)$ & $37.7(1,546)^{\mathrm{c}}$ \\
\hline & Third level, \%(n) & $35.7(1451)$ & $23.2(953)^{\mathrm{c}}$ \\
\hline \multirow[t]{2}{*}{ Living arrangements } & With others, \% (n) & $83.7(3,07)$ & $71.7(2,947)$ \\
\hline & Alone, \% (n) & $16.3(661)$ & $28.3(1,160)^{c}$ \\
\hline \multirow[t]{3}{*}{ Smoking } & Never, \% (n) & $45.9(1870)$ & $41.3(1,698)$ \\
\hline & Previous, \% (n) & 39.3 (1597) & $37.0(1,519)$ \\
\hline & Current, \% (n) & $14.8(601)$ & $21.7(890)^{\mathrm{c}}$ \\
\hline \multirow[t]{3}{*}{ Physical activity } & Low, \% (n) & $27.0(1098)$ & $37.1(1,494)$ \\
\hline & Moderate, \% (n) & 36.1 (1469) & $32.7(1,317)^{c}$ \\
\hline & High, \% (n) & $36.9(1501)$ & $30.2(1,214)^{c}$ \\
\hline \multirow[t]{3}{*}{ Body mass index } & Normal, \% (n) & $22.1(900)$ & $23.0(407)$ \\
\hline & Overweight, \% (n) & $44.3(1801)$ & $40.6(720)$ \\
\hline & Obese, \% (n) & $33.6(1367)$ & $36.4(646)$ \\
\hline \multirow[t]{3}{*}{ No. of chronic conditions } & None, \% (n) & $48.8(1984)$ & $46.0(1,401)$ \\
\hline & $1, \%(n)$ & $34.0(1384)$ & $35.0(1,435)$ \\
\hline & $\geq 2, \%(\mathrm{n})$ & $17.2(700)$ & $19.0(779)^{\mathrm{a}}$ \\
\hline \multirow[t]{3}{*}{ No. of CV conditions } & None, \% (n) & $37.9(1545)$ & $34.1(1,293)$ \\
\hline & $1, \%(n)$ & $33.2(1349)$ & $34.4(1,413)^{b}$ \\
\hline & $\geq 2, \%(\mathrm{n})$ & $28.9(1174)$ & $31.5(1,293)^{c}$ \\
\hline $\begin{array}{l}\text { Global cognition, MMSE } \\
\text { errors }\end{array}$ & Mean (SD) & $1.4(1.8)$ & $2.4(2.8)^{\mathrm{c}}$ \\
\hline \multirow[t]{2}{*}{ Depression, CES-D score } & $<16, \%(\mathrm{n})$ & $88.9(3626)$ & $91.8(3,773)$ \\
\hline & $\geq 16, \%(\mathrm{n})$ & $11.1(442)$ & $8.2(334)^{\mathrm{c}}$ \\
\hline No. of medications & Mean (SD) & $2.0(2.3)$ & $2.7(2.7)^{\mathrm{c}}$ \\
\hline \multirow[t]{2}{*}{ No. of supplements } & $0, \%(n)$ & $82.3(3348)$ & $83.0(3,424)$ \\
\hline & $\geq 1, \%(\mathrm{n})$ & $17.7(720)$ & $17.0(683)$ \\
\hline \multirow[t]{2}{*}{ Disability: ADL/IADL } & $0, \%(\mathrm{n})$ & $91.9(3738)$ & $84.0(3,451)$ \\
\hline & $\geq 1, \%(\mathrm{n})$ & $8.1(330)$ & $16.0(656)^{\mathrm{c}}$ \\
\hline \multirow[t]{3}{*}{ Phenotype frailty } & Nonfrail, \% (n) & $68.8(2799)$ & $53.0(2,177)$ \\
\hline & Prefrail, \% (n) & $29.3(1192)$ & $38.3(1,573)^{c}$ \\
\hline & Frail, \% (n) & $1.9(77)$ & $8.7(357)^{\mathrm{c}}$ \\
\hline \multirow[t]{3}{*}{ FI } & Nonfrail, \% (n) & $60.9(2479)$ & $50.9(2,092)$ \\
\hline & Prefrail, \% (n) & $29.8(1211)$ & $30.9(1,268)^{c}$ \\
\hline & Frail, \% (n) & $9.3(378)$ & $18.2(747)^{\mathrm{c}}$ \\
\hline \multirow[t]{3}{*}{ FRAIL Scale } & Nonfrail, \% (n) & $80.7(3282)$ & $(2,919)$ \\
\hline & Prefrail, \% (n) & $18.0(733)$ & $24.6(1,000)^{\mathrm{c}}$ \\
\hline & Frail, \% (n) & $1.3(53)$ & $4.6(188)^{c}$ \\
\hline
\end{tabular}

Significance level is indicated by ${ }^{\mathrm{a}} P \leq .05,{ }^{\mathrm{b}} P<.01$, and ${ }^{\mathrm{c}} P<.001$.

Adapted from Roe et al. ${ }^{49}$ 
Supplementary Table 3

Minimally Adjusted (Model 2) Associations Between Standardized Log-Transformed Biomarkers and Frailty Status for Phenotype, FI, and FRAIL Scale Instruments

\begin{tabular}{|c|c|c|c|c|c|c|}
\hline \multirow[t]{3}{*}{ Micronutrient } & \multicolumn{2}{|l|}{ Phenotype } & \multicolumn{2}{|l|}{ FI } & \multicolumn{2}{|l|}{ FRAIL scale } \\
\hline & Prefrail & Frail & Prefrail & Frail & Prefrail & Frail \\
\hline & RRR (95\% CI) & RRR (95\% CI) & RRR (95\% CI) & RRR (95\% CI) & RRR (95\% CI) & RRR (95\% CI) \\
\hline Lutein & $0.86^{\mathrm{C} *}(0.79-0.93)$ & $0.43^{\mathrm{c} *}(0.34-0.54)$ & $0.80^{\mathrm{C} *}(0.73-0.87)$ & $0.63^{\mathrm{c} *}(0.75-0.81)$ & $0.78^{\mathrm{c} *}(0.70-0.86)$ & $0.46^{\mathrm{C} *}(0.36-0.58)$ \\
\hline Zeaxanthin & $0.87^{\mathrm{C} *}(0.80-0.95)$ & $0.49^{\mathrm{c} *}(0.38-0.64)$ & $0.79^{\mathrm{C} *}(0.73-0.86)$ & $0.63^{\mathrm{C} *}(0.55-0.72)$ & $0.81^{\mathrm{c} *}(0.73-0.90)$ & $0.53^{\mathrm{C} *}(0.40-0.69)$ \\
\hline Folate & $0.90^{\mathrm{b} *}(0.83-0.97)$ & $0.80^{\dagger}(0.66-1.03)$ & $1.01(0.94-1.10)$ & $0.94(0.83-1.07)$ & $0.87^{\mathrm{b} *}(0.79-0.95)$ & $0.96(0.70-1.31)$ \\
\hline Vitamin B-12 & $0.92^{\mathrm{a}}(0.85-0.99)$ & $0.97(0.71-1.31)$ & $1.03(0.95-0.12)$ & $0.97(0.85-1.11)$ & $0.91^{\mathrm{a}}(0.83-0.99)$ & $1.08(0.78-1.50)$ \\
\hline Vitamin D & $0.80^{\mathrm{C} *}(0.74-0.87)$ & $0.58^{\mathrm{c} *}(0.48-0.70)$ & $0.93(0.86-1.01)$ & $0.75^{\mathrm{c} *}(0.67-0.85)$ & $0.82^{\mathrm{c} *}(0.74-0.91)$ & $0.51^{\mathrm{c} *}(0.39-0.67)$ \\
\hline No. of insufficiencies & $1.20^{\mathrm{C} *}(1.12-1.28)$ & $1.90^{\mathrm{c} *}(1.58-2.30)$ & $1.14^{\mathrm{c} *}(1.07-1.23)$ & $1.42^{\mathrm{C} *}(1.29-1.56)$ & $1.27^{\mathrm{c} *}(1.18-1.36)$ & $1.87^{\mathrm{c} *}(1.56-2.24)$ \\
\hline
\end{tabular}

Adjusted for age, age $^{2}$, sex, and education.

Significance is indicated by ${ }^{\mathrm{a}} P \leq .05,{ }^{\mathrm{b}} P<.01$, and ${ }^{\mathrm{c}} P<.001$.

*FDR-corrected significance level $P<.0361$.

${ }^{\dagger}$ Significance is indicated by $P \leq .09$.

\section{Supplementary References}

1. Fried LP, Ferrucci L, Darer J, et al. Untangling the concepts of disability, frailty, and comorbidity: Implications for improved targeting and care. J Gerontol A Biol Sci Med Sci 2004;59:255-263.

2. Fried LP, Tangen CM, Walston J, et al. Frailty in older adults: evidence for a phenotype. J Gerontol A Biol Sci Med Sci 2001;56(3):M146-M156.

3. Moran R, Nolan JM, Stack J, et al. Non-Dietary Correlates and Determinants of Plasma Lutein and Zeaxanthin Concentrations in the Irish Population. J Nutr Health Aging 2017;21(3):254-261.
4. Nolan JM, Loskutova E, Howard AN, et al. Macular pigment, visual function, and macular disease among subjects with Alzheimer's disease: an exploratory study. J Alzheimers Dis 2014;42(4):1191-1202.

5. Kelleher BP, Broin SD. Microbiological assay for vitamin B12 performed in 96well microtitre plates. J Clin Pathol 1991;44(7):592-595.

6. Molloy AM, Scott JM. Microbiological assay for serum, plasma, and red cell folate using cryopreserved, microtiter plate method. Methods Enzymol 1997;281:43-53.

7. Laird E, O'Halloran AM, Carey D, et al. The Prevalence of Vitamin D Deficiency and the Determinants of 25(OH)D Concentration in Older Irish Adults: Data From The Irish Longitudinal Study on Ageing (TILDA). J Gerontol A Biol Sci Med Sci 2018;73(4):519-525. 